\title{
Tarefas Alternativas para o Ensino e a Aprendizagem de Funções: análise de uma intervenção no Ensino Médio
}

\section{Alternative Tasks for the Teaching and the Learning of functions: analysis of an intervention in the High School}

\author{
Renata Cristina Geromel Meneghetti" \\ Julyette Priscila Redling**
}

\begin{abstract}
Resumo
Neste artigo focalizamos a aplicação de duas tarefas matemáticas alternativas para o ensino e a aprendizagem de funções, junto a alunos do Ensino Médio. Tais tarefas foram elaboradas levando-se em consideração a seguinte abordagem metodológica: (i) resolução de problemas e/ou investigação matemática e (ii) uma proposta pedagógica que defende o desenvolvimento do conhecimento matemático mediante um equilíbrio entre lógica e intuição. Utilizamos uma abordagem de pesquisa qualitativa (caracterizada como estudo de caso) para analisar o potencial didático-pedagógico deste tipo de metodologia no Ensino Médio. Verificamos que tarefas, tais como as que serão apresentadas e discutidas neste artigo, favorecem uma aprendizagem mais significativa aos alunos, permitindolhes maior compreensão conceitual, e tornam-se ainda mais potentes quando se considera o contexto sócio-cultural dos alunos.

\footnotetext{
"Doutora em Educação Matemática pelo Instituto de Geociências e Ciências Exatas da Universidade Estadual Paulista (IGCE-UNESP), Campus Rio Claro, SP. Docente do Instituto de Ciências Matemáticas de Computação da Universidade de São Paulo (ICMC-USP), São Carlos, SP, Brasil. Endereço para correspondência: Avenida do trabalhador são-carlense, n.400, centro C.P. 668, CEP: 13560-970. São Carlos, SP, Brasil. E-mail: rcgm@icmc.usp.br.

*** Mestre pelo Programa de Pós-graduação em Educação para Ciência da Faculdade de Ciências da Universidade Estadual Paulista (UNESP), Campus Bauru. No momento da realização do levantamento de dados desta pesquisa era bolsista de iniciação científica (FAPESP) e aluna de graduação do curso de Licenciatura em Ciências Exatas - Habilitação em Matemática, Curso Interunidades: Instituto de Física de São Carlos (IFSC), Instituto de Ciências Matemáticas e de Computação (ICMC) e Instituto de Química de São Carlos (IQSC) da Universidade de São Paulo (USP), São Carlos, São Paulo, Brasil. Endereço para correspondência: Rua Jorge Chamas Sobrinho, 465 - Jd Margarida, CEP: 13630-620. Pirassununga, SP, Brasil. E-mail: jredling@gmail.com.
} 
Palavras-chave: Funções. Investigação Matemática. Resolução de Problemas. Proposta Pedagógica. Ensino Médio. Aprendizagem Significativa.

\begin{abstract}
In this paper we focus on the application of two mathematical alternative tasks to the teaching and learning of functions with high school students. The tasks were elaborated according to the following methodological approach: (i) Problem Solving and/or mathematics investigation and (ii) a pedagogical proposal, which defends that mathematical knowledge is developed by means of a balance between logic and intuition. We employed a qualitative research approach (characterized as a case study) aimed at analyzing the didactic pedagogical potential of this type of methodology in high school. We found that tasks such as those presented and discussed in this paper provide a more significant learning for the students, allowing a better conceptual understanding, becoming still more powerful when one considers the social-cultural context of the students.
\end{abstract}

Keywords: Functions. Mathematics Investigation. Problem Solving. Pedagogical Proposal. High School. Meaningful Learning.

\title{
1 Introdução
}

A Matemática no Ensino Médio, na maioria das vezes, tem sido marcada pela tendência que Fiorentini (1995) denomina de tecnicista, segundo a qual a matemática se reduz a um conjunto de técnicas, regras, algoritmos, sem grande preocupação em fundamentá-los ou justificá-los. Esse autor coloca, ainda, que tal tendência foi marcante no ensino brasileiro de matemática, principalmente no final dos anos 60 até o final dos anos de 70. Entretanto, percebe-se que, nesse nível de ensino, esse é um aspecto que persiste, embora historicamente outras tendências, como a construtivista e a socioetnocultural, tenham surgido no ensino de matemática no Brasil.

Essa percepção é fruto do contato que a primeira autora deste artigo tem tido com o ensino e a aprendizagem de matemática no Ensino Médio, tanto por meio dos estágios supervisionados da disciplina de Prática de Ensino, ministrada pela mesma desde 1996, nos cursos de licenciatura de uma Universidade Pública do Estado de São Paulo, quanto por meio de coordenação de plantões de dúvidas de matemática, oferecidos aos alunos da Educação Básica, durante vários anos, como atividade vinculada ao Centro de Divulgação Cultural e Científica da Universidade de São Paulo (CDCC-USP). 
No âmbito geral, as Orientações Educacionais Complementares aos Parâmetros Curriculares Nacionais, PCN+ Ensino Médio, destacam que, tradicionalmente, no Brasil, o Ensino Médio organizou-se em duas modalidades: (i) a pré-universitária e (ii) a profissionalizante. A primeira, enfatizando uma divisão disciplinar do aprendizado; a segunda, o treinamento para afazeres práticos (BRASIL, 2002). Entende-se, portanto, que a partir de tais diretrizes, o Ensino Médio passou a ser concebido como parte integrante da Educação Básica, portanto o acesso é direito de todo cidadão. ${ }^{1} \mathrm{O}$ Ensino Médio como complementação da Educação Básica, em qualquer modalidade, tem por missão “[...] preparar para a vida, qualificar para a cidadania e capacitar para o aprendizado permanente, em eventual prosseguimento dos estudos ou diretamente no mundo de trabalho" (BRASIL, 2002, p. 8).

De acordo com a Lei de Diretrizes e Bases da Educação Nacional (L.D.B. n. 9.394/96), o Ensino Médio tem como finalidades centrais não apenas a consolidação e o aprofundamento dos conhecimentos adquiridos durante o nível fundamental, no intuito de garantir a continuidade de estudos, mas também a preparação para o trabalho e para o exercício da cidadania, a formação ética, o desenvolvimento da autonomia intelectual e a compreensão dos processos produtivos.

Nessa definição de propósitos, percebe-se que a escola de hoje não pode mais ficar restrita ao ensino disciplinar, de natureza enciclopédica. De acordo com as Orientações Curriculares para o Ensino Médio (BRASIL, 2006) deve-se considerar um amplo espectro de competências e habilidades a serem desenvolvidas no conjunto das disciplinas.

No que se refere à Matemática, os Parâmetros Curriculares Nacionais (PCN) enfatizam que "O Ensino Médio precisa desenvolver o saber matemático científico e tecnológico como condição de cidadania e não como prerrogativa de especialistas". (BRASIL, 1999, p. 210). Ao final desse nível, segundo as Orientações Curriculares para o Ensino Médio, espera-se que os alunos saibam usar a matemática para resolver problemas do cotidiano, para modelar fenômenos em outras áreas do conhecimento, que eles compreendam que a matemática é uma ciência com características próprias, que percebam a matemática como um conhecimento social e historicamente construído, e que saibam apreciar a importância da matemática no desenvolvimento científico e tecnológico. (BRASIL, 2006).

\footnotetext{
${ }^{1}$ L.D.B n. 9.394/96 (BRASIL, 1999b, p. 46 - 47).
} 
Tais fatos exigem novas orientações teóricas e metodológicas para esse nível de ensino. Com intuito de colaborar com outras abordagens metodológicas, e refletir sobre as mesmas, focalizamos, neste artigo, a aplicação de uma metodologia alternativa para o ensino e aprendizagem da Matemática do Ensino Médio. Esta visa proporcionar ao aluno deste nível uma aprendizagem mais significativa dos conceitos matemáticos, em prol de ambos objetivos: (i) a formação do aluno enquanto cidadão e (ii) a preparação para o ensino universitário, buscando propostas didáticas que favoreçam a comunicação e argumentação, compreensão e investigação de problemas, construção de conceitos matemáticos, desenvolvimento de atitudes de aprendizagem e de convívio social. (BRASIL, 1999).

A respeito da passagem do Ensino Médio para o Ensino Universitário, atualmente sabemos que, embora em proporções diferentes, dois instrumentos têm sido fundamentais para o acesso do aluno ao Ensino Superior: os vestibulares e o Exame Nacional do Ensino Médio (ENEM). Esse processo de admissão ao Ensino Superior cria no aluno uma expectativa muito grande com respeito ao Ensino Médio. Levando isso em consideração, propomos trabalhar essa etapa de ensino seguindo uma abordagem diferente da tradicional, porém usando questões dos vestibulares e dos ENEM como ponto de partida, visto que, pelo menos uma parte dos alunos nessa fase, está motivada para ingressar no Ensino Superior - poder cursar uma faculdade faz parte dos anseios profissionais de muitos desses alunos. Logo, a estratégia metodológica foi de aproveitar esse fator favorável e tentar desenvolver um trabalho alternativo para o Ensino Médio, como segue.

Partindo de questões dos vestibulares $\left(\mathrm{A}^{2}\right.$ e $\left.\mathrm{B}^{3}\right)$ e dos ENEM, elaboramos algumas tarefas alternativas para o ensino de funções, considerando a seguinte abordagem metodológica: (i) resolução de problemas, e/ou investigações matemática; e (ii) a proposta de Meneghetti (2001) e Meneghetti e Bicudo (2003), na qual se procura desenvolver o conhecimento matemático mediante um equilíbrio entre os aspectos lógico e intuitivo desse conhecimento, em níveis cada vez mais elaborados, num processo dinâmico, que ocorre de forma espiral.

Na resolução de problemas o conteúdo a ser aprendido pode ser iniciado

\footnotetext{
${ }^{2}$ Fundação responsável pela realização dos exames vestibulares de algumas escolas de nível superior do Estado de São Paulo, inclusive de uma Universidade Pública de São Paulo de grande representatividade e importância.

${ }^{3}$ Responsável pela realização do vestibular de uma importante universidade pública do estado de São Paulo e outras universidades públicas e particulares, além de concursos públicos do Estado de São Paulo.
} 
por meio de um problema desafio (ou um conjunto de problemas deste tipo), devendo ocorrer uma construção interiorizada do conhecimento a ser adquirido. (GAZIRE, 1988). Nas atividades investigativas é importante apresentar aos alunos um conjunto de propostas de trabalho interessantes, que envolvam conceitos matemáticos fundamentais e lhes ofereçam oportunidades para experimentar, discutir, formular, conjeturar, generalizar, provar, comunicar as suas ideias e tomar decisões. (SERRAZINA et al., 2002).

Por tarefa entende-se, segundo Ponte et al. (1997), uma dada situação de aprendizagem proposta pelo professor - problemas, investigações, exercícios etc. - a qual aponta para certo conteúdo matemático, e que proporciona o ponto de partida para o desenvolvimento da atividade matemática. $\mathrm{O}$ termo atividade é designado, por esses autores, como sendo aquilo que o aluno faz num dado contexto, ou seja, suas ações na execução de determinada tarefa.

Neste artigo focalizamos a aplicação de duas dessas tarefas, visando investigar a viabilidade de tal proposta, do ponto de vista didático-pedagógico para o Ensino Médio. Especificamente, no caso tratado, abordamos o tema funções. Com isso, nosso propósito passou a ser o de avaliar os principais aspectos referentes à estruturação das tarefas elaboradas para o ensino de funções, com o intuito de verificar se as mesmas proporcionariam aos alunos uma aprendizagem mais significativa dos conceitos envolvidos.

No que segue, apresentamos as considerações teóricas que fundamentam esta pesquisa, que são referentes ao Ensino Médio, ao ensino de funções, às tarefas de cunho investigativo, à proposta pedagógica utilizada e à aprendizagem significativa. Depois, abordamos os aspectos metodológicos desta investigação, em seguida, há uma descrição do material empregado e de sua aplicação. Por fim, analisamos a aplicação efetuada e traçamos alguns resultados.

\section{Algumas considerações referentes à matemática no Ensino Médio}

Os PCN (BRASIL, 1999, p. 111) afirmam que "o conhecimento matemático é necessário em uma grande variedade de situações, como apoio a outras áreas do conhecimento, sendo também instrumento para lidar com situações cotidianas, ou como forma de desenvolver habilidades de pensamento". No Ensino Médio, etapa final da Educação Básica, a Matemática deve ser compreendida como uma parcela do conhecimento humano, essencial para a formação de todos os jovens, proporcionando a construção de uma visão de mundo, para ler e interpretar a realidade e para desenvolver capacidades que deles serão exigidas ao longo da vida social e profissional. 
Ainda, segundo esses parâmetros, nessa etapa da escolaridade, a matemática vai além de seu caráter instrumental, colocando-se como ciência, com características próprias de investigação e de linguagem e com papel integrador importante junto às demais Ciências da Natureza. Aprender matemática de uma forma contextualizada, integrada e relacionada a outros conhecimentos traz em si o desenvolvimento de competências e habilidades que são fundamentalmente formadoras, à medida que familiarizam o aluno, capacitando-o para compreender e interpretar situações, para se apropriar de linguagens específicas, argumentar, analisar e avaliar, tirar conclusões próprias, tomar decisões, generalizar, entre outras ações necessárias à sua formação.

As atuais Orientações Curriculares para o Ensino Médio (BRASIL, 2006) destacam que a forma de trabalhar os conteúdos matemáticos deve, sempre, agregar um valor formativo no que diz respeito ao desenvolvimento do pensamento matemático. Isso significa colocar os alunos em um processo de aprendizagem que valorize o raciocínio matemático.

[...] parte-se do princípio de que toda situação de ensino e aprendizagem deve agregar o desenvolvimento de habilidades que caracterizem o "pensar matematicamente". Nesse sentido, é preciso dar prioridade à qualidade do processo e não à quantidade de conteúdos a serem trabalhados. A escolha de conteúdos deve ser cuidadosa e criteriosa, propiciando ao aluno um "fazer matemático" por meio de um processo investigativo que o auxilie na apropriação de conhecimento. (BRASIL, 2006, p.70).

Segundo a Proposta Curricular (SÃO PAULO, 1991), há duas vertentes básicas, amplamente difundidas, a partir das quais se justifica a inclusão da Matemática nos currículos escolares: (a) ela é necessária em ações práticas que envolvem aspectos quantitativos e (b) desenvolve o raciocínio lógico, a capacidade de abstrair, generalizar, projetar aquilo que é imediatamente sensível.

No entanto, tal proposta ainda salienta que não é tão simples entrar em um acordo sobre o modo como um currículo deve ser estruturado para que tais objetivos sejam alcançados. Assim, algumas vezes, uma ênfase exagerada em aspectos práticos pode não ultrapassar o senso comum. Outras vezes, pretendese o desenvolvimento das estruturas lógicas do pensamento através de caminhos tão formais e tão distanciados de qualquer significado imediato que o ensino de matemática parece apenas um efetivo exercício para o desenvolvimento do raciocínio.

Esses dois aspectos são, de fato, componentes básicos e essenciais no 
currículo, não sendo, contudo, qualquer um deles suficiente para caracterizar o papel que a matemática deve desempenhar. Para o entendimento da função desempenhada pela matemática no currículo, aplicações práticas e desenvolvimento do raciocínio devem ser considerados elementos inseparáveis. Conseguir uma situação de equilíbrio é a maior e mais difícil tarefa do professor de matemática.

A Proposta Curricular atual (SÃO PAULO, 2008) relata que a Matemática é considerada um meio para o desenvolvimento de competências, tais como, a capacidade de expressão pessoal, de compreensão de fenômenos, de argumentação, de tomada de decisões conscientes e refletidas e de problematização e assimilação dos conteúdos estudados em diferentes contextos.

As orientações presentes nessa última Proposta Curricular não podem ser compreendidas como algo fechado e inflexível. A organização curricular, como é apresentada, tem o objetivo de estabelecer uma articulação de conteúdos, entre as diversas formas possíveis. Assim, espera-se que, com a abordagem dos conteúdos sugerida para a grade curricular, sejam privilegiadas algumas ideias fundamentais, de natureza transdisciplinar, que servirão de intermediárias na mobilização das temáticas para o desenvolvimento das competências pessoais dos alunos, bem como para a construção dos significados dos conteúdos estudados. (SÃO PAULO, 2008).

\subsection{Algumas considerações sobre o ensino e a aprendizagem de Função}

No Ensino Médio, o tema Função aparece como um conteúdo vinculado à Álgebra. Sobre essa última, Alonso e Moraes (2003) enfatizam que o deve constituir uma forma de refletir aspectos da realidade, isto é, de compreender e descrever os movimentos da vida. Porém, estes autores salientam que o modo como os professores vêm trabalhando os conceitos algébricos em sala de aula, dando maior importância ao formalismo, ao rigor matemático, à memorização, à repetição dos conteúdos, e às fórmulas, ao invés de transferir o cotidiano dos alunos para a sala, faz com que os conceitos algébricos acabem se tornando de difícil entendimento para os alunos.

Segundo Fiorentini, Miorin e Miguel (1993), tradicionalmente o ensino de álgebra se sustenta na crença de que o pensamento algébrico somente manifesta-se e desenvolve-se a partir do cálculo literal. No entanto, essa relação de subordinação do pensamento algébrico à linguagem desconsidera o fato de que a linguagem algébrica é, também, resultado de uma forma especial de 
pensamento e de leitura do mundo, não se reduzindo somente a um instrumento técnico-formal para facilitar a resolução de certos problemas. Na busca por uma caracterização do pensamento algébrico, esses autores concluem que não existe uma única forma de se expressar o pensamento algébrico. Embora essa forma de pensamento se manifeste em todos os campos da matemática e de outras áreas do conhecimento, tal manifestação não significa, apenas, a aplicação da álgebra no sentido instrumental. Mais do que isso, o pensamento algébrico está na base da construção e da compreensão desses campos e áreas. Por fim, esses autores indicam como elementos caracterizadores do pensamento algébrico: a percepção de regularidades e de aspectos invariantes, as tentativas de expressar ou explicitar a estrutura de uma situação-problema e o processo de generalização.

Para Fiorentini, Fernandes e Cristovão (2005) a realização de tarefas exploratório-investigativas visa levar os alunos a pensar de maneira genérica, percebendo regularidades e explicitando-as através de expressões matemáticas. Esta pode ser uma alternativa poderosa para o desenvolvimento inter-relacionado do pensamento e da linguagem algébrica dos alunos, caracterizando este tipo de atividade como mais uma concepção de educação algébrica. Por tarefas exploratório-investigativas esses autores entendem aquelas que tendem a ser mais livres e menos sistemáticas que as demais, usadas para introduzir um novo tema de estudo ou para problematizar e produzir significados a um conceito matemático, permitindo, aos alunos, várias alternativas de exploração e investigação.

Os PCN (BRASIL, 1999) colocam que a Álgebra, na vivência cotidiana, se apresenta com grande importância enquanto linguagem, como na variedade de gráficos presentes diariamente nos noticiários e jornais, e, também, enquanto instrumento de cálculos de natureza financeira e prática, em geral. No Ensino Médio, esse tema aborda números e variáveis em conjuntos infinitos e quase sempre contínuos, no sentido de serem completos. Os objetos de estudo são os campos numéricos dos números reais e, eventualmente, os números complexos, as funções e as equações de variáveis ou incógnitas reais. Os procedimentos básicos desse tema se referem a calcular, resolver, identificar as variáveis, traçar e interpretar gráficos e resolver equações, de acordo com as propriedades das operações no conjunto dos números reais e as operações válidas para o cálculo algébrico. O tema Álgebra apresenta fortemente o caráter de linguagem, com seus códigos (números e letras) e regras (propriedades das operações), formando os termos desta linguagem, denominados expressões, que, por sua vez, compõem as igualdades e desigualdades. 
O estudo das funções possibilita ao aluno assimilar a linguagem algébrica como a linguagem das ciências, necessária para expressar relações entre grandezas e estruturar situações-problema, construindo modelos descritivos de fenômenos e permitindo várias conexões, dentro e fora da própria matemática. Assim, a ênfase no estudo dos diferentes tipos de funções deve estar no conceito de função e em suas propriedades relativas às operações, na interpretação de seus gráficos e nas aplicações dessas funções (BRASIL, 1999).

\section{Acerca da resolução de problemas e das tarefas investigativas}

A definição de problema dada por Polya $\left(1962^{6}\right.$, p.117) apud Fonseca, Brunheira e Ponte (1999) diz, num sentido amplo, que há um problema quando existe a procura "consciente de uma certa ação apropriada para obter um objetivo claramente concebido mas não atingível de maneira imediata".

Para Pozo (1998), um problema se distingui de um exercício, na medida em que para este dispomos de procedimentos que nos levam de maneira imediata à solução. Todavia, é possível que uma mesma situação seja encarada como um problema para uma pessoa, enquanto para outra seja um simples exercício, se esta possuir mecanismos e recursos cognitivos mínimos para resolvê-la. A concepção de problema para Onuchic (1999) pode ser enunciada como sendo tudo aquilo que não se sabe fazer, mas que existe interesse em resolver, isto é, qualquer situação que leve o aluno a pensar e que lhe seja desafiadora e não trivial.

Na resolução de problemas o conteúdo a ser aprendido pode ser iniciado através de um problema desafio (ou um conjunto de problemas deste tipo), devendo ocorrer uma construção interiorizada do conhecimento a ser adquirido (GAZIRE, 1988). Segundo Pinheiro (2005), o principal objetivo ao se trabalhar com a resolução de problemas na matemática é levar o educando a entender a resolução de problemas como um processo, onde o principal interesse está no raciocínio desenvolvido, e não apenas na resposta encontrada.

De acordo com os PCN (BRASIL, 1999), na resolução de problemas o tratamento de situações complexas e diversificadas oferece ao aluno a oportunidade de pensar por si mesmo, construir estratégias de resolução e argumentações, relacionar diferentes conhecimentos e, enfim, perseverar na busca da solução. Para Romanatto (2008), a resolução de problemas se apresenta como um dos caminhos mais promissores para o fazer matemática dentro da sala de aula.

${ }_{6}^{6}$ POLYA, G. Mathematical Discovery. New York: John Wiley, 1962. 
No entanto, de acordo com Fonseca, Brunheira e Ponte (1999), a noção de problema foi progressivamente enriquecida, ao se considerar importante proporcionar aos alunos não apenas problemas já perfeitamente elaborados. Muitas vezes, o processo de resolução de problema pode implicar a exploração do contexto para além do que surge no enunciado, e a formulação de questões alternativas. Nesse sentido, um novo tipo de abordagem foi se delineando, tratase da investigação matemática. Nessa última, sabe-se qual é o ponto de partida, mas não o ponto de chegada, diferentemente dos problemas, que objetivam encontrar um caminho para alcançar um ponto não imediatamente acessível.

Segundo Ponte (2003, p. 26), “investigar não é mais do que procurar conhecer, compreender, encontrar soluções para os problemas com os quais nos deparamos". Ainda, George Polya ( $1975^{7}$, p. vii apud PONTE; BROCARDO; OLIVEIRA, 2003, p. 15 - 16) chama-nos a atenção para o contraste entre duas imagens da matemática: "A matemática tem duas faces; é a ciência rigorosa de Euclides, mas é também algo mais [...] a matemática em construção aparece como uma ciência experimental, indutiva".

Uma investigação matemática desenvolve-se, geralmente, em torno de um ou mais problemas. O primeiro grande passo de qualquer investigação é identificar claramente o problema a ser resolvido, por isso, não é de se admirar que, em matemática, exista uma relação muito próxima entre problemas e investigações.

Entretanto, a resolução de problemas e a investigação matemática possuem aspectos diferentes, pois, como aponta Ponte e Matos (1998, p. 119): Nas investigações matemáticas os alunos são colocados no papel dos matemáticos [...]. Envolvem processos de raciocínio complexos e requerem um elevado grau de empenhamento e criatividade por parte do aluno. Envolvem, no entanto, também alguns processos característicos. Enquanto os problemas matemáticos tendem a caracterizarse por assentarem em dados e objectivos bem concretos, as investigações têm um ponto de partida muito menos definido.

Segundo Ponte (2003), num problema o enunciado indica, claramente, o que é dado e o que é pedido, e a solução é sabida de antemão pelo professor; numa investigação matemática, a construção do conhecimento, por parte dos

7 POLYA, G. A arte de resolver problemas. Rio de Janeiro: Interciência, 1975. 
alunos, se dá de uma forma não sistêmica, trata-se de situações abertas, cabendo a quem investiga um papel fundamental em sua definição, na qual os pontos de partida e chegada podem variar.

Desse modo, Ernest (1996, p. 30) afirma que "enquanto o processo de resolução de problemas em matemática é descrito como convergente, as investigações matemáticas são divergentes".

Nesse sentido, a investigação matemática, essencialmente, permite que os alunos façam matemática, isto é, que eles tenham seu próprio pensar e não sejam conduzidos a respostas pré-estabelecidas. Com isso, este tipo de trabalho possibilita enfrentar a matemática como algo que as pessoas fazem, e não como algo que as pessoas já fizeram (FONSECA, 2000a).

Conclui-se, então, que uma investigação tem um caráter necessariamente problemático, mas permite a elaboração de diversos tipos de questões, estimulando a exploração em várias direções. O interesse está, sobretudo, nas ideias matemáticas e nas suas relações, cabendo ao aluno um papel ativo na definição das questões a investigar, e, ao professor, uma nova postura em dar continuidade às questões propostas pelos alunos.

Assim, de acordo com Ponte (2003), pode-se dizer que a realização de uma investigação matemática está ligada a quatro momentos principais:

- o primeiro abrange o reconhecimento da situação e a elaboração de questões;

- o segundo refere-se ao processo de formulação de conjeturas;

- o terceiro inclui a realização de testes;

- o quarto diz respeito à argumentação, à demonstração e à avaliação do trabalho realizado.

Para Serrazina et al. (2002, p. 41) neste tipo de atividade "é importante apresentar aos alunos um conjunto de propostas de trabalho interessantes, que envolvam conceitos matemáticos fundamentais e ofereçam aos alunos oportunidades para experimentar, discutir, formular, conjecturar, generalizar, provar, comunicar as suas ideias e tomar decisões." Acrescenta-se, ainda, que, segundo Ponte (2003) uma tarefa investigativa pode ser contextualizada numa situação real ou formulada em termos puramente matemáticos.

Em síntese, podemos dizer que as investigações matemáticas referemse a situações-problema desafiadoras e abertas, permitindo aos alunos apresentarem várias formas de explorar e investigar o problema.

Para Fiorentini; Fernandes; Cristovão (2005), a utilização de tarefas investigativas nas aulas de matemática constitui uma perspectiva de trabalho pedagógico da qual o professor pode lançar mão para a realização de um ensino significativo da matemática. 
Segundo Serrazina et al. (2002), o conceito de investigação matemática, como atividade de ensino-aprendizagem, ajuda a trabalhar dentro da sala de aula o espírito da atividade matemática genuína, constituindo, por isso, uma importante ferramenta educativa, além de proporcionar uma experiência produtiva em nível dos processos envolvidos na matemática e no pensamento matemático.

Diversos trabalhos, tais como Goldenberg (1999), Fonseca (2000b), e Ponte, Brocardo e Oliveira (2003), têm apontado que tarefas investigativas motivam os alunos e favorecem a aprendizagem e a criação de um ambiente propício para a mesma. Por motivos como esses, os autores acima defendem que investigações matemáticas podem se constituir num poderoso processo de construção de conhecimento.

Quanto à resolução de problemas, a importância da utilização dessa abordagem em sala de aula também é defendida por diversos autores, dentre eles Mandarino (2002), Onuchic (1999) e Carvalho (1994), os quais afirmam que com a resolução de problemas tem-se a oportunidade de propiciar um diálogo maior entre professor-aluno, aluno-aluno, na busca de soluções para os problemas, promovendo um ambiente rico para aprender matemática, na medida em que esse diálogo proporciona uma maior aproximação dos alunos com os professores, facilitando a verificação dos caminhos trilhados na busca da resposta dos problemas e da apreensão dos conhecimentos matemáticos; e dos próprios alunos que, ao trabalharem em grupos, podem se ajudar mutuamente, utilizando seus conhecimentos prévios.

Outro ponto importante, destacado por Rodrigues (2006), é que o trabalho com a metodologia de resolução de problemas oportuniza ao aluno criar estratégias na busca de solução para o problema, justificá-las, dando-lhe oportunidade de modificar seus conhecimentos prévios e construir novos significados. Além disso, esse autor ressalta que, o trabalho com problemas possibilita desenvolver o processo de contextualização, inserindo-os no contexto social dos alunos, dando um sentido para os mesmos a respeito do que se quer ensinar e porque se deve aprender.

Dessa forma, nessa pesquisa, optamos por trabalhar com resolução de problemas e investigação matemática devido ao potencial didático-pedagógico que ambas possuem na direção de contribuir com o processo de ensino e aprendizagem dos estudantes, sendo concebidas como novas formas de se ensinar e aprender a matemática escolar. 


\section{Proposta pedagógica do equilíbrio entre os aspectos intuitivo e lógico do conhecimento matemático}

Filósofos e matemáticos, desde a época de Platão, nem sempre estiveram de acordo quanto à natureza do saber matemático. A esse respeito, Meneghetti (2001) e Meneghetti e Bicudo (2003), ao analisarem as concepções de conhecimento geral e conhecimento matemático nas principais correntes filosóficas, de Platão (427 - 347 a. C.) ao início do século XX, chegam às seguintes considerações.

Antes de Kant (1724-1804), na História da Filosofia da Matemática, foi possível obter duas posições: (a) aqueles que buscaram fundamentar o saber matemático inteiramente na razão - entendemos que nesse grupo há prevalência do aspecto lógico do conhecimento; e (b) aqueles que buscaram fundamentar o saber matemático exclusivamente na intuição ou experiência - entendemos que nesse grupo é privilegiado o aspecto intuitivo do conhecimento.

Uma posição intermediária aos dois grupos é possível ser verificada em Kant, para o qual todo conhecimento parte da experiência. Entretanto, o conhecimento deve tornar-se independente dela, pois a ciência deve ser universal e necessária. Essa posição, no entanto, foi abandonada nas filosofias que pretendiam dar conta da natureza do conhecimento matemático, no final do século XIX e início do século XX, a saber, o logicismo, o formalismo e o intuicionismo. O fato é que, embora essas três correntes filosóficas tenham tentado fornecer à matemática uma fundamentação sólida, todas falharam em seus propósitos, e a natureza do saber matemático passou a ser novamente questionada. (SNAPPER, 1979 apud MENEGHETTI; BICUDO, 2003).

Meneghetti e Bicudo (2003) procuram mostrar que tal crise é produto de se considerar, sempre, os aspectos intuitivo e lógico do conhecimento matemático como excludentes e, a partir desse estudo, propõem que no processo de constituição desse conhecimento não seja possível atribuir maior valor para o aspecto intuitivo ou para o lógico, ou mesmo concebê-los como independentes. Eles ainda defendem que o intuitivo apoia-se no lógico e vice-versa, em níveis cada vez mais elaborados, num processo gradual e dinâmico, tomando a forma de uma espiral, sendo que o equilíbrio entre os aspectos lógico e intuitivo deve estar presente em cada um dos níveis dessa espiral.

Segundo Meneghetti (2009), embora o termo intuitivo possa tomar diversos significados, em tal proposta esse termo é concebido como um conhecimento de apreensão imediata, sem intermediário, podendo ser de origem 
empírica (conhecimento empírico) ou a priori (conhecimento que não depende da experiência). ${ }^{8}$ Inspirada nos trabalhos de Frege $(1979,1959)$, a lógica, neste caso, está sendo considerada como uma linguagem puramente formal, que não necessita ser suplementada por qualquer razão intuitiva. Assim, entende essa autora que é por meio da lógica que sistematizamos, ou seja, formalizamos o conhecimento, e o mesmo adquire o caráter de necessidade e universalidade.

Numa análise das correntes filosóficas da matemática pós-crise dos fundamentos, essa última autora observa que ideias colocadas na proposta em questão ganham força quando consideramos as atuais reivindicações para a Filosofia da Matemática, que, entre outras contribuições, reconhecem a importância dos aspectos empírico e intuitivo na constituição do saber matemático, além de refutar o caráter absoluto de tal conhecimento.

A questão do equilíbrio dinâmico para os aspectos lógico e intuitivo desse saber, abordada por tal proposta no que se refere ao processo de elaboração do conhecimento, mostra uma afinidade com o que é posto nas ideias de construtivismo social, tal como colocado por Ernest (1991) ${ }^{9}$ apud Meneghetti (2009); essas ideias defendem que o conhecimento subjetivo ${ }^{10}$ relaciona-se com o conhecimento objetivo ${ }^{11}$ por meio de um ciclo criativo, através do qual um contribui para a renovação do outro.

Quanto aos níveis no processo de constituição do conhecimento, defendidos pela proposta, esses podem ser justificados cognitivamente com Vygotsky (1991) ${ }^{12}$ apud Meneghetti (2009), o qual afirma que, à medida que o intelecto se desenvolve, velhas generalizações são substituídas por generalizações de tipos cada vez mais elevados. A aquisição de conceitos novos e mais elevados transforma os significados dos conceitos anteriores.

Determinada análise de uma aplicação da proposta descrita acima para o caso de frações - é tratada em Meneghetti e Nunes (2006), em que se discute sobre a fundamentação, elaboração, aplicação e avaliação de um material pedagógico desenvolvido como suporte para o processo de ensino-aprendizagem dos números racionais. Dessa aplicação, esses autores chegam à conclusão de que a proposta metodológica que estrutura o material, aliada a uma postura em

\footnotetext{
${ }^{8}$ Esse foi um dos sentidos adotado por Kant, sendo escolhido em primeiro lugar por ser genérico - ao conceber o intuitivo como um conhecimento de apreensão imediata - e, em segundo lugar, por reconhecer que esse tipo de conhecimento pode ser tanto de natureza empírica como a priori.

${ }^{9}$ ERNEST, P. The philosophy of mathematics education. London: Falmer.1991.

${ }^{10}$ Referente à criação pessoal do indivíduo.

${ }^{11}$ No sentido de ser socialmente aceito.

12 VYGotSky, L. Pensamento e linguagem. 3.ed. São Paulo: M. Fontes, 1991.
} 
consonância com seu suporte teórico, mostrou-se eficiente do ponto de vista didático-pedagógico, por favorecer aos alunos a construção dos conceitos matemáticos envolvidos.

\section{A aprendizagem significativa}

Ausubel, Novak e Hanesian (1978) ao analisarem a interação entre professor, aluno e conhecimento, dentro do contexto escolar, identificaram duas formas de aprendizagem: a mecânica e a significativa. A aprendizagem significativa advém quando o indivíduo relaciona o conteúdo a ser aprendido com aquilo que ele já sabe, sendo capaz de generalizar e expressar esse conteúdo com sua própria linguagem, isto é, quando as novas informações interagem com estruturas de conhecimento do indivíduo, às quais Ausubel define como subsunçores.

Quando não se consegue estabelecer essa relação e a formulação da, diz-se que houve aprendizagem mecânica, isto é, o indivíduo só consegue expressar as ideias repetindo as mesmas palavras, memorizando-as, sem ter, de fato, assimilado os conteúdos envolvidos. Os conhecimentos aprendidos desse modo só são aplicáveis a situações já conhecidas, que não impliquem compreensão, e, assim, não instrumentalizam o indivíduo para agir de forma autônoma na sua realidade (MOREIRA, 1999).

Assim, numa aprendizagem mecânica, o sujeito armazena um novo conhecimento arbitrariamente, ou seja, sem realizar ligações com outros conteúdos.

Os conceitos de subsunçores têm fundamental papel na teoria de Ausubel. Moreira e Masini (1982) esclarecem que os mesmos referem-se às ideias-âncoras, pré-existentes na estrutura cognitiva do indivíduo. Então, tais conceitos facilitam a ocorrência de aprendizagem significativa, na qual os novos conceitos são relacionados, de maneira não-arbitrária, a outros já apreendidos.

Ainda segundo Ausubel, Novak e Hanesian (1978), favorecer a aprendizagem significativa implica verificar em que parte do continuum, isto é, em quais da várias posições intermediárias do conhecimento, está o conhecimento do aluno e, desse modo, é preciso promover diferentes oportunidades de interação. Nessa perspectiva, a qualidade dos procedimentos de ensino depende da relação destes com as características dos sujeitos, do tempo e dos espaços envolvidos; são estes aspectos que mostram a posição intermediária do ensino no processo educativo. 
A aprendizagem se torna muito mais significativa à medida que o novo conceito é relacionado às estruturas de conhecimento do aluno, e adquire significado a partir da relação com seu conhecimento prévio. Caso isso não aconteça, ela se torna mecânica ou repetitiva, o novo conteúdo passa a ser guardado isoladamente ou através de associações arbitrárias na estrutura cognitiva. Portanto, quando não existe um esforço consciente para relacionar o novo conhecimento, a aprendizagem será mecânica, e, consequentemente, será esquecida mais facilmente. (NOVAK, 1981).

De acordo com a teoria de Ausubel (1982), a aprendizagem significativa apresenta três vantagens essenciais em relação à aprendizagem memorística. Em primeiro lugar, o conhecimento adquirido de maneira significativa é armazenado e lembrado por mais tempo. Em segundo, amplia a capacidade de aprender outros conteúdos de um modo mais fácil, mesmo se a informação original for esquecida. Em terceiro, uma vez esquecida a informação original, facilita a aprendizagem seguinte, ou seja, a reaprendizagem, por assim dizer. Em especial, sobre esse último ponto, Novak (1981) esclarece que é possível relacionar novas informações mesmo após o aparente esquecimento, pois o conceito subsunçor inicial fora modificado, com isso os dados guardados poderão ser recordados, o que não acontece quando temos uma aprendizagem mecânica.

No entanto, segundo Moreira (1999), para que a aprendizagem significativa ocorra são necessárias duas condições. Primeiro, o aluno precisa ter disposição para aprender, relacionando assim o novo conceito de maneira não-arbitrária. Segundo, o conteúdo escolar a ser aprendido tem que ser potencialmente significativo, isto é, tem que ser lógica e psicologicamente significativo. Acrescenta esse autor que o lógico depende da natureza do conteúdo e o psicológico é uma experiência atribuída a cada indivíduo.

Desse modo, a intervenção educativa precisa ser concebida numa outra perspectiva, na qual não se vise somente a compreensão do saber, mas também o saber fazer; e não tanto o aprender, mas o aprender a aprender. Para isso, é necessário que a ação educativa esteja coerente com o nível de desenvolvimento dos alunos; para que isso ocorra, é preciso identificar os conhecimentos prévios dos alunos.

Em síntese, o que se sugere é a participação ativa do sujeito na construção do conhecimento, o que pressupõe a participação efetiva do aluno na aquisição de novos saberes, de maneira que esses não sejam uma mera repetição ou cópia dos formulados pelo professor ou pelo livro-texto, mas uma re-elaboração pessoal. O aluno é o ponto de partida para a organização do ensino, o qual, por 
sua vez, só terá sido bem sucedido se o aluno, agora sendo considerado como ponto de chegada, tiver aprendido significativamente os conteúdos curriculares. Ou seja, na Teoria da Aprendizagem Significativa, proposta por Ausubel e aperfeiçoada por seus seguidores, o ensino é apenas um meio pelo qual a aprendizagem significativa do estudante pode ser favorecida.

\section{Metodologia}

As tarefas elaboradas, seguindo a abordagem descrita anteriormente, foram aplicadas em um minicurso, sob coordenação da primeira autora deste trabalho $^{13}$, a uma classe de treze alunos da terceira série do Ensino Médio, de uma escola pública do interior do Estado de São Paulo/Brasil, mediante acordo estabelecido com a professora de matemática desta turma.

A realização do minicurso se deu de forma vinculada aos estágios supervisionados da disciplina Prática de Ensino de Matemática, sob a docência da segunda autora, denominada aqui de professora-aplicadora (PA), e sob orientação da primeira. O minicurso também fez parte do desenvolvimento de projeto de Iniciação Científica (com apoio da Fundação de Amparo à Pesquisa do Estado de São Paulo - FAPESP).

Buscando atender aos objetivos do projeto, a intervenção realizada inserese numa abordagem qualitativa de pesquisa, seguindo os pressupostos de um estudo de caso. Este, segundo Ludke e André (1986), possui as seguintes características: enfatiza a interpretação em contexto, busca retratar a realidade de informação; revela experiências, utiliza-se de linguagem acessível que pode ser apresentada na forma de desenhos, fotografias, colagens, discussões etc.

O trabalho de campo seguiu as seguintes etapas: (i) aplicação de um questionário de identificação e realização de uma avaliação diagnóstica inicial (para um levantamento dos conhecimentos prévios dos alunos); (ii) aplicação das tarefas elaboradas; e (iii) avaliação do minicurso. Durante o desenvolvimento das tarefas propostas foi permitido aos alunos usar calculadora e consultar livros didáticos.

Como instrumentos de coleta de dados, utilizamos relatórios da aplicação, informações referentes à avaliação diagnóstica inicial e relatórios dos alunos a respeito dos procedimentos utilizados no desenvolvimento das atividades. Além

\footnotetext{
${ }^{13} \mathrm{Na}$ ocasião a primeira autora deste trabalho colaborava com o CDCC (Centro de Divulgação Cultural e Científica-USP) na coordenação de atividades de matemática para alunos do Ensino Fundamental e Médio oferecidas por este centro.
} 
disso, combinamos as anotações das observações com o material transcrito de gravações e filmagens.

\section{Descrição do material}

Neste trabalho focalizamos a aplicação de duas tarefas alternativas. A primeira foi reformulada a partir de uma questão do ENEM, e a segunda do vestibular B. Ao elaborarmos as atividades propostas, nos preocupamos em trabalhar com situações que abordassem o assunto funções, procurando desenvolvê-las em níveis cada vez mais elaborados, buscando por um equilíbrio entre os aspectos intuitivo e lógico do conhecimento, além de tentar apresentálas de forma a terem uma abordagem investigativa e/ou de resolução de problemas. Anteriormente, uma aplicação dessas tarefas havia sido efetuada pela autora (com acompanhamento da segunda) em uma disciplina de Prática de Ensino de um curso de Licenciatura em Matemática, o que permitiu aos futuros professores vivenciar a abordagem de um conteúdo de matemática por meio de uma metodologia alternativa e, também, um aprimoramento do material.

Abaixo apresentamos as tarefas em suas formas originais, seguido das tarefas reformuladas (que foram propostas aos alunos). Na sequência, fazemos um comentário das tarefas quanto a suas adequações à abordagem de resolução de problemas e/ou investigação matemática.

\section{TAREFA \\ QUESTÃOORIGINAL}

\section{ENEM}

\section{VENDEDORESJOVENS}

\section{Fábrica de LONAS - Vendas no Atacado}

10 vagas para estudantes, 18 a 20 anos, sem experiência.

Salário: $\mathrm{R} \$ 300,00$ fixo + comissão de $\mathrm{R} \$ 0,50$ por $\mathrm{m}^{2}$ vendido.

Contato: 0xx97-43421167 ou atacadista@ lonaboa.com.br

Na seleção para as vagas deste anúncio, feita por telefone ou correio eletrônico, propunha-se aos candidatos uma questão a ser resolvida na hora. Deveriam calcular seu salário no primeiro mês, se vendessem $500 \mathrm{~m}$ de tecido com largura de $1,40 \mathrm{~m}$, e no segundo mês, se vendessem o dobro. Foram bem sucedidos os jovens que responderam, respectivamente,
(A) $\mathrm{R} \$ 300,00$ e $\mathrm{R} \$ 500,00$.
(B) $\mathrm{R} \$ 550,00$ e $\mathrm{R} \$ 850,00$. 
(C) $\mathrm{R} \$ 650,00$ e $\mathrm{R} \$ 1000,00$.

(D) $\mathrm{R} \$ 650,00$ e $\mathrm{R} \$ 1300,00$.

(E) $\mathrm{R} \$ 950,00 \mathrm{e} \mathrm{R} \$ 1900,00$.

\section{TAREFAPROPOSTA}

Imagine que seu amigo esteja procurando emprego, e que você, para ajudá-lo, compra um jornal e seleciona os seguintes anúncios:

\section{- Vendedores de lona}

10 vagas para estudantes, 18 a 20 anos, com experiência.

Salário: $\mathrm{R} \$ 350,00^{*}+$ comissão de $\mathrm{R} \$ 0,50$ por $\mathrm{m}^{2}$ vendido.

- Vendedores de loja

8 vagas para pessoas com idade entre 18 e 35 anos, sem experiência.

Salário: R $\$ 630,00$ + comissão de $6 \%$ sobre o valor total de venda por mês.

\section{- Vendedores autônomos}

Trabalhe vendendo os produtos de nosso catálogo (cosméticos, roupas, utensílios domésticos, eletroeletrônicos, bijuterias, etc.) e ganhe de $20 \%$ a $35 \%$ sobre cada produto vendido.

Você seria capaz de verificar qual dessas propostas de emprego seria mais vantajosa para seu amigo? Existe alguma que será sempre mais vantajosa que as outras? Estude vários casos e justifique.

\subsection{Comentário à primeira tarefa}

Na primeira tarefa, tem-se por objetivo levar o aluno a identificar a função inerente à situação-problema (no caso, trata-se de uma função afim) utilizando somente seus conhecimentos prévios. Esta tarefa enquadra-se na abordagem de investigação matemática, pois possui um caráter aberto (do princípio ao fim), nessa o aluno é livre para encontrar as mais variadas soluções por meio de uma diversidade de caminhos.

No desenvolvimento das atividades investigativas, o processo de resolução pode implicar a exploração, a partir da situação apresentada, de todos os caminhos que surgem como importantes para além do que surge no enunciado, e, também, estimular a formulação de questões alternativas. Entretanto, é sabido que a investigação matemática desenvolve-se geralmente em torno de um ou mais problemas. Dessa forma, conclui-se, então, que uma investigação tem um caráter necessariamente problemático, mas, ao permitir a elaboração de diversos tipos de questionamentos, estimular a exploração em várias direções, possibilita a obtenção de mais de uma resposta correta para a mesma situação, diferenciandose assim da abordagem de resolução de problema, na qual existe um único resultado previamente concebido. 


\section{$2^{\text {a TAREFA }}$ \\ QUESTÃOORIGINAL \\ Vestibular B}

09. Num período prolongado de seca, a variação da quantidade de água de certo reservatório é dada pela função

$$
\mathrm{q}(\mathrm{t})=\mathrm{q}_{0} \cdot 2^{(-0,1) \mathrm{t}}
$$

sendo $\mathrm{q}_{0}$ a quantidade inicial de água no reservatório e $\mathrm{q}(\mathrm{t})$ a quantidade de água no reservatório após t meses. Em quantos meses a quantidade de água do reservatório se reduzirá à metade do que era no início?
(A) 5 .
(B) 7 .
(C) 8 .
(D) 9 .
(E) 10 .

\section{TAREFAPROPOSTA}

Você é o dono de uma fazenda que está passando por um período prolongado de seca. Nela existe um reservatório que é controlado para não desperdiçar água. Sabendo-se que no início do período de seca o reservatório estava cheio, isto é, com sua capacidade máxima, indicada por $\mathrm{q}_{0}$, desafio você a responder:

a) Se ao final do $1^{\circ}$ mês de seca, o reservatório ficou com metade $(50.000 \mathrm{~L})$ da quantidade inicial de água $\left(\mathrm{q}_{0}\right)$ e que no $2^{\circ}$ mês a quantidade de água chegou a $12.500 \mathrm{~L}$, você saberia dizer o que acontecerá ao final do sexto mês de seca(se essa tendência se mantiver)? Você poderia dizer como se comportou a variação de água nesse período? A partir de suas respostas anteriores seria possível escrever uma expressão que pudesse representar essa situação?

b) Se no ano anterior, no mesmo período, a quantidade de água desse reservatório após o $1^{\circ}$ mês de seca, chegou a $49.998 \mathrm{~L}$ e no $2^{\circ}$ mês a quantidade diminuiu para 24.995 L, o que você poderia concluir ao final do sexto mês de seca (se essa tendência se mantiver)? Como se comportou a variação de água nesse período? É possível escrever uma expressão que pudesse representar essa situação?

c) Como você poderia explicar o fenômeno ocorrido no mesmo período de seca em anos diferentes, se o reservatório é o mesmo? Investigue as possibilidades.

d) Você conseguiria explicar esse fenômeno matematicamente? Descreva tudo o que você conseguir relacionar.

\footnotetext{
* Na época em que o material foi aplicado esse valor correspondia ao salário mínimo do Brasil.
} 


\subsection{Comentário à segunda tarefa}

Nessa segunda tarefa proposta, um dos objetivos principais é que o aluno consiga relacionar os diferentes tipos de funções presentes na atividade (nesse caso, a função exponencial e a função afim). Entendemos que essa tarefa possui um caráter investigativo, no sentido de que o aluno é levado a investigar cada uma das situações, havendo a possibilidade de seguir diferentes caminhos para a resolução dessa atividade. Entretanto, visto que se pressupõe que há uma solução determinada para cada uma das situações, essa tarefa não atenderia o quesito, característico de uma investigação matemática, de poder chegar a diferentes resultados. Nesse sentido, entendemos que essa tarefa aproxima-se mais da abordagem de resolução de problemas.

\section{Aplicação do material}

Inicialmente PA explicou aos alunos em que consistiria o minicurso e o que seria focalizado. A partir daí, solicitou-se que eles respondessem a um questionário de identificação, contendo informações pessoais (idade, endereço etc.). Em seguida, foi aplicada uma avaliação diagnóstica inicial, que teve por finalidade verificar os conhecimentos prévios dos alunos.

Durante a fase de aplicação do material, os alunos foram organizados em grupos de livre escolha. Entendemos que essa forma de organização é importante na construção dos conceitos, pois, segundo Mauri (2003, p. 92), "a atividade desenvolvida pelo aluno na construção dos conhecimentos não pode ser realizada de maneira solitária, justamente pela natureza dos saberes culturais. O aluno precisa do auxílio de outros, que o ajudem no processo de representação ou atribuição de significados". Além disso, o trabalho em grupo proporciona ao professor um melhor contato com os alunos, prestando ajuda adequada quando necessário, conforme o grau de realização da tarefa e das dificuldades apresentadas por eles. (ZABALA, 2003).

Referente a cada uma dessas tarefas, que foram realizadas em dias diferentes, depois da formação dos grupos de trabalho e da entrega da folha de atividades do dia, PA realizava uma leitura da tarefa para os alunos, visando esclarecer alguns termos que pudessem levar a dúvidas posteriores. Na sequência, os alunos resolviam as atividades. Após os alunos terminarem suas resoluções, PA promovia uma discussão das mesmas e os conceitos envolvidos em cada situação, visando também formalizar o que foi trabalhado. 
A intenção desse fechamento foi promover, nesse nível, o que Meneghetti e Bicudo (2003) defendem, a saber, um equilíbrio entre os aspectos intuitivo e lógico do conhecimento. Além disso, do ponto de vista da abordagem metodológica de investigação matemática, segundo Ponte (2003), o fechamento corresponde ao quarto e último momento da aplicação de atividades deste tipo, consistindo na argumentação e demonstração dos conceitos envolvidos, sendo importante para a sistematização e formalização desses conceitos, a fim de que se tornem compreensíveis aos alunos.

\section{Análise da aplicação}

\subsection{Sobre o questionário e o diagnóstico inicial}

Por meio do questionário inicial, constatamos que os alunos dessa sala pertenciam a uma faixa etária entre 17-18 anos e residiam na zona rural. Além disso, verificamos que a principal fonte de informação dos alunos sobre assuntos relacionados à Álgebra eram, respectivamente, livros didáticos e aulas expositivas. Os alunos também responderam que já haviam aprendido o tema função no primeiro ano do Ensino Médio, mas não recordavam muita coisa porque, segundo eles, o assunto havia sido tratado superficialmente. Vale salientar que, como posto no referencial teórico, o fácil esquecimento de um assunto é típico de uma aprendizagem mecânica. (NOVAK, 1981). Assim, a aplicação de uma avaliação diagnóstica inicial nos indicou, também, que a aprendizagem destes assuntos (no primeiro ano do Ensino Médio) não foi significativa, pois dois anos após terem estudado o tema, os alunos pouco se lembravam das questões abordadas.

A avaliação diagnóstica inicial se compôs de exercícios que envolviam: definir função; verificar se uma relação representava ou não uma função; identificar domínio, contradomínio e imagem de uma função; construir gráficos de funções. Ademais, essa avaliação trouxe três situações-problema, abrangendo, respectivamente, função do $1^{\circ}$ grau, do $2^{\circ}$ grau e exponencial.

Tal avaliação foi muito importante, pois permitiu-nos identificar os conhecimentos prévios dos alunos e as dificuldades que eles apresentavam quanto ao tema funções. Observamos que, dos 13 alunos que participaram dessa avaliação, a maioria apresentava dificuldades em definir precisamente o conceito de função, fato que certamente se apresentaria como um obstáculo na compreensão de outros conceitos relacionados com esse. Segue uma exemplificação: 


\section{1) Você sabe dizer a que è uma função? Que tipos de funções você conhece?}

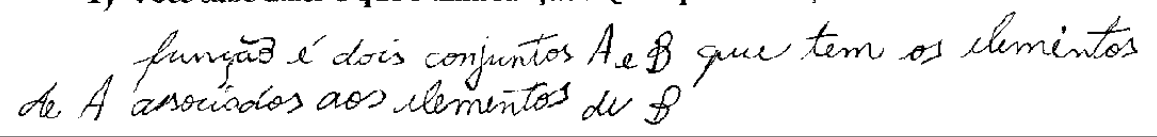

Figura 1- Definição de um aluno sobre o conceito de função

Neste caso, percebe-se que o aluno, apesar de mostrar alguma familiaridade com os termos, não consegue expressar adequadamente o conceito de função, parece não compreender uma função como sendo uma correspondência entre cada elemento do conjunto A com um único elemento do conjunto B.

No exercício 2, demos quatro relações e solicitamos que os alunos verificassem se eram funções ou não e, a partir disso, definissem seus domínios, contradomínios e imagens. Somente quatro alunos conseguiram executar a atividade. Os demais, embora tenham conseguido identificar corretamente que duas relações representavam funções e as outras duas não, apresentaram dificuldades conceituais com respeito às definições de domínio, contradomínio e imagem (Figura 2).

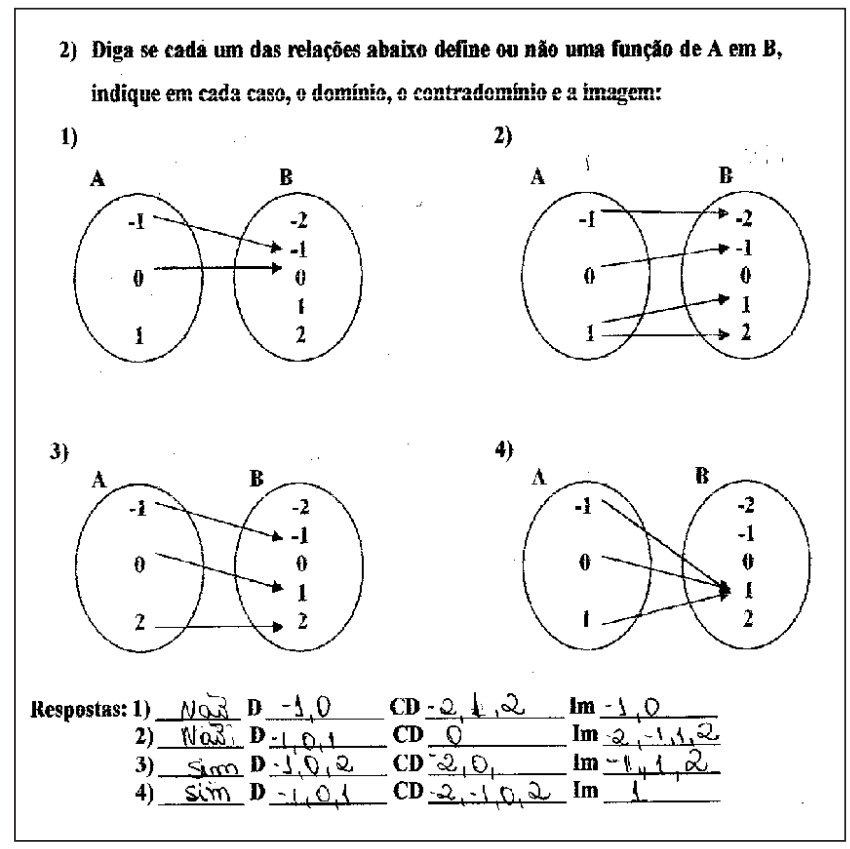

Figura 2 - Identificação do domínio, contradomínio e imagem a partir das relações 
Nesta figura, observamos que embora as relações 1 e 2 não representem funções, os campos de domínio, contradomínio e imagem foram preenchidos. Além disso, observamos, ainda, que referentes aos casos 3 e 4 os contradomínios são concebidos como o conjunto complementar da imagem da função, e não como o conjunto de chegada da função.

No exercício 3 solicitava-se que, a partir da observação de alguns gráficos, os alunos identificassem quais deles representavam uma função. Verificamos que a maioria dos alunos conseguiu executar a tarefa. Porém, em suas justificativas, eles se pautaram em traçar uma linha vertical sobre o gráfico e verificar se a mesma o cortava em um único ponto.

Com relação às três situações-problema que constavam dessa avaliação, que envolviam função de $1^{\circ}$ grau, $2^{\circ}$ grau e exponencial, foi solicitado que os alunos resolvessem os problemas, identificassem, para cada um deles, a função correspondente e sua representação gráfica. Ficou evidente, nas duas primeiras situações (ver enunciados em nota de rodapé) ${ }^{14}$ que a maioria dos alunos, embora tenha conseguido resolver e identificar as funções correspondentes a cada situação-problema, teve muitas dificuldades na construção dos gráficos ${ }^{15}$, como exemplificado nas figuras 3 e 4 abaixo.
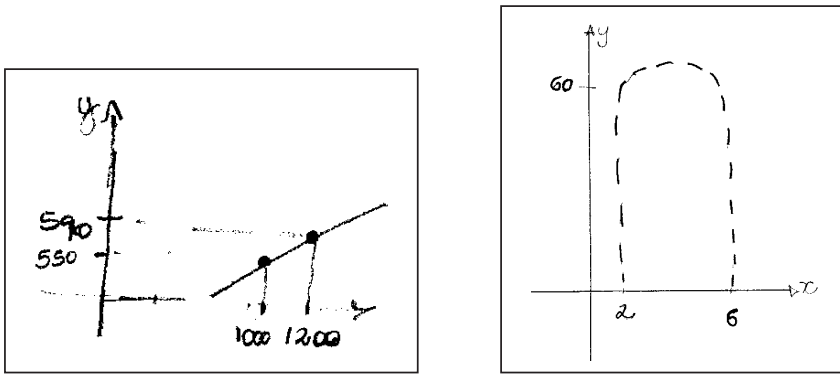

Figuras 3 e 4 - Representação incorreta dos gráficos das funções

\footnotetext{
${ }^{14}$ Situação - problema 1): A remuneração de um vendedor de uma loja de calçados é feita em duas parcelas. Uma parcela fixa de $\mathrm{R} \$ 350,00$ e uma parcela variável correspondente a uma comissão de $20 \%$ do total de vendas realizadas no mês. Construa a função descrita nesta situação, identifique-a e represente-a graficamente. Se esse vendedor vender $\mathrm{R} \$ 1.200,00$ em mercadoria no mês, quanto ele receberá? E se ele vender $\mathrm{R} \$ 1.000,00$ ?

Situação - problema 2): Uma bola é lançada do solo verticalmente para cima e tem sua posição em função do tempo expressa pela função $\mathrm{H}(\mathrm{t})=40 \mathrm{t}-5 \mathrm{t}^{2}$, onde $\mathrm{H}$ representa a altura em metros e $\mathrm{t}$ representa o tempo em segundos. Em quais instantes a bola estará a uma altura de 60 metros? Identifique o tipo de função que é trabalhada nesse exercício e a represente graficamente.

$\mathrm{Na}$ situação-problema (quarto exercício) que envolvia função do $1^{\circ}$ grau, 11 alunos conseguiram resolvê-la e 10 identificá-la; no quinto exercício, 9 alunos conseguiram resolver e identificar como sendo do $2^{\circ}$ grau a função presente na situação-problema proposta.

${ }^{15}$ Com relação à construção dos gráficos, 11 alunos não conseguiram construir corretamente o gráfico representando a função do $1^{\circ}$ grau e 9 erraram na construção do gráfico da função do $2^{\circ}$ grau.
} 
A reta do gráfico mostrado na figura 3, correspondente à primeira situação-problema, deveria cortar o eixo das ordenadas no ponto 350, representando a parcela fixa do salário do vendedor. Quanto à figura 4, correspondente a segunda situação-problema, percebemos que o aluno conseguiu identificar que a parábola que representava o movimento de uma bola lançada verticalmente do solo teria a concavidade voltada para baixo, mas não representou a continuidade da função nem a informação de que a bola fora lançada do solo, ou seja, $\mathrm{H}(0)=0$.

Quanto à terceira situação-problema, correspondente ao sexto exercício do diagnóstico ${ }^{16}$, observamos que a maioria dos alunos não conseguiu resolver o problema e nem identificar o tipo de função, demonstrando dificuldade com o conceito e com as características de uma função exponencial.

\subsection{Sobre as tarefas alternativas}

A respeito da análise da aplicação das tarefas alternativas, chegamos às seguintes considerações. Sobre a primeira, percebemos que os alunos se interessaram bastante pelo trabalho, mas mostraram-se confusos quanto ao que fazer. Acreditamos que isso tenha ocorrido por eles não estarem acostumados a trabalhar com esse tipo de tarefa. Porém, o fato da mesma versar sobre um assunto familiar aos alunos, contribuiu muito para despertar o interesse deles pelo problema. Eles conseguiram estabelecer comparações entre as propostas sem precisar fazer uso de definições formais. Nessa perspectiva, segundo Ausubel (1982), o ensino ideal é aquele que, desenvolvido em função de um planejamento que considera a realidade (cognitiva, afetiva, social) do aluno ou grupo de alunos, proporciona situações que lhe(s) possibilite(m) aprender significativamente determinados conhecimentos. Com isso, entendemos que esse tipo de contextualização foi bastante importante para o envolvimento inicial dos alunos com as tarefas propostas.

Verificamos, em relação às possíveis soluções da primeira atividade, que diversas situações foram simuladas na tentativa de encontrar a melhor. Os alunos justificaram detalhadamente cada uma delas, fazendo uma comparação de todas as exigências necessárias para pleitear as vagas de emprego das três

\footnotetext{
${ }^{16}$ Inicia-se a criação de certa bactéria em um laboratório. Estudos indicam que o número inicial é de 200 bactérias. A cada duas horas a quantidade dobra. A fórmula que representa esta situação é dada por: $\mathrm{N}(\mathrm{t})=\mathrm{N}_{0} \cdot \mathrm{K}^{\mathrm{t}}$, onde: $\mathrm{N}_{0}$ - número inicial de bactérias, $\mathrm{t}$ - tempo e $\mathrm{K}$ - constante. Determine o numero de bactérias, 12 horas após o início do estudo. Que tipo de função está sendo trabalhada nesta situação? Represente-a graficamente.
} 
propostas. Eles conseguiram apresentar uma análise de qual das propostas era a mais vantajosa, como pode ser observado no excerto a seguir, tirado do relatório de um dos grupos:

Pensamos nos três possíveis casos de vendas. No primeiro, do vendedor de lona, achamos um pouco menos vantajoso pelo fato de exigir experiência. Já no segundo caso, do vendedor de loja, a vantagem é melhor, pois não é necessário experiência e o salário é mais vantajoso do que o primeiro. E o terceiro caso, do vendedor autônomo, é um pouco melhor e um pouco ruim. O lado bom é porque não precisa ter entre 18 e 20 anos como no primeiro anúncio, nem ter de 18 a 35 anos, como no segundo, e também não é necessário ter experiência. O lado ruim é que o salário não é fixo e sim $20 \%$ a $35 \%$ do valor de cada produto vendido. Achamos que o emprego mais vantajoso será dos vendedores de loja, porque terá um salário fixo e uma comissão de $6 \%$ do total de vendas do mês; e também porque mesmo ele não vendendo a mercadoria ele irá ganhar o salário fixo. Mas nem sempre será a mais vantajosa, porque dependerá dos valores que serão vendidos.

Quanto ao cálculo dos salários de cada proposta, como os alunos não sabiam que estavam trabalhando com uma tarefa que envolvia o conceito de função do $1^{\circ}$ grau, eles criaram suas próprias estratégias para conseguir calcular os valores dos salários. Somente um grupo conseguiu representar as funções de cada proposta. Os outros três utilizaram a regra de três em suas resoluções, como no exemplo abaixo:

Vendedor autônomo

$20 \%$ a $35 \%$ sobre cada produto

\begin{tabular}{|c|c|c|}
\hline Cosmético $=\mathrm{R} \$ 20,00$ & $22 \%$ & $100 x=440$ \\
\hline Ganhou $22 \%$ na venda $=\mathrm{R} \$ 4,40$ & $100 \% \_20$ & $x=4,4$ \\
\hline Roupa $=\mathrm{R} \$ 10,00$ & $20 \%$ & $100 x=200$ \\
\hline Ganhou $20 \%$ na venda $=R \$ 2,00$ & $100 \%$ & $x=2$ \\
\hline Utensílio Doméstico $=\mathrm{R} \$ 5,00$ & $20 \%$ & $100 x=100$ \\
\hline Ganhou $20 \%$ na venda $=\mathrm{R} \$ 1,00$ & $100 \%$ & $x=1$ \\
\hline Eletro-Eletrônico $=\mathrm{R} \$ 500,00$ & $35 \%-x$ & $100 x=17500$ \\
\hline Ganhou $35 \%$ na venda $=R \$ 175,00$ & $100 \%-500$ & $x=175$ \\
\hline
\end{tabular}


$\begin{array}{lll}\text { Bijuteria }=\mathrm{R} \$ 5,00 & 20 \% & 100 \mathrm{x}=100 \\ \text { Ganhou } 20 \% \text { na venda }=\mathrm{R} \$ 1,00 & 100 \%-5 & \mathrm{x}=1\end{array}$

Total $=\mathrm{R} \$ 183,4$ por dia

$\mathrm{R} \$ 183,4$ x 20 dias $=\mathrm{R} \$ 3.668,00$ por mês

Assim, todos conseguiram desenvolver a atividade e chegar a uma conclusão quanto à proposta mais vantajosa, manifestando uma disposição para relacionar de maneira substancial e não arbitrária o novo material, fato necessário no contexto da aprendizagem significativa. (MOREIRA, 1995). Com isso, constatamos que essa tarefa favoreceu o desenvolvimento da criatividade dos alunos, abrindo possibilidades para diversas maneiras de solucionar o problema a partir de seus conhecimentos prévios, sem que eles precisassem, de antemão, dos conceitos formais sobre o assunto, evidenciando, assim, de acordo com Moreira (1982), o que pode se chamar de uma aprendizagem por descoberta, a qual se caracteriza como aprendizagem significativa a partir do momento que os alunos, ao utilizarem seus conhecimentos prévios, estabeleceram ligações entre o conteúdo descoberto e os conceitos subsunçores relevantes, já existentes em suas estruturas cognitivas.

Quanto à análise da aplicação da segunda tarefa, percebemos que a maioria dos grupos apresentou um raciocínio muito parecido na resolução dos itens (a) e (b), e resolveram-nos experimentalmente, não conseguindo chegar a uma expressão que representasse as correspondentes funções. Ilustramos isto na figura 5, abaixo, referente à resolução do item (a) desta tarefa por um dos grupos.

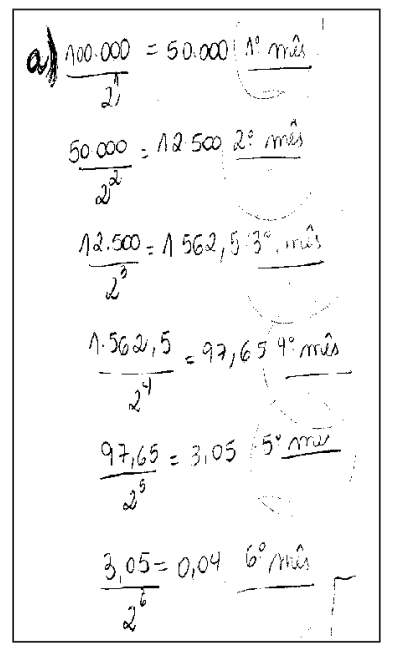

Figura 5 - Resolução do item A por um dos grupos. 
Entretanto, um dos grupos nos chamou a atenção, pois conseguiu encontrar as funções que representavam as duas situações e construir seus respectivos gráficos. Como pode ser visto na figura 6 , referente à resolução do item (b):

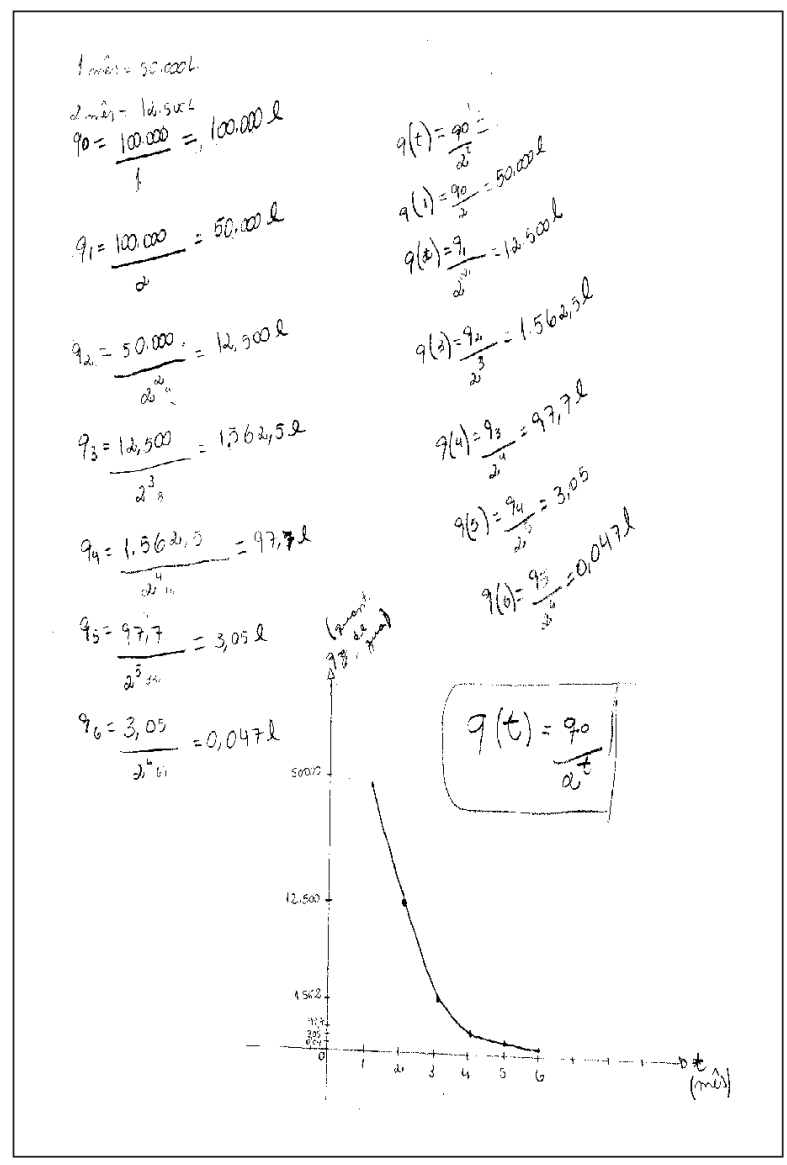

Figura 6 - Representação gráfica e algorítmica da função presente no item B

Para justificar o item (c), interdisciplinar, todos os grupos responderam que, sendo o reservatório o mesmo, o fator que o levou a esvaziar mais em um ano do que no outro foi o período de seca, mais rigoroso, que levou a um gasto maior de água. Porém, o item (d), em que se pedia que se explicasse matematicamente o fenômeno da seca, não foi respondido por nenhum grupo.

Com isso, concluímos que apesar dos alunos terem conseguido trabalhar 
com as funções presentes nesta tarefa, muitos ainda demonstraram ter bastante dificuldade quanto à generalização e a construção de seus gráficos. Essa situação evidenciou a dificuldade que os alunos têm em generalizar e formalizar os conceitos, reforçando a importância do professor em atuar como mediador nessa passagem.

Verificamos, portanto, que é possível, com este tipo de tarefa, partindo dos conhecimentos prévios dos alunos, aos poucos chegar aos conceitos formais dos conteúdos abordados. Assim, a passagem do intuitivo para o lógico foi sendo obtida paulatinamente, em diversos momentos, exigindo uma forte atuação do professor nessa direção.

Vale esclarecer que o diagnóstico inicial foi essencial para verificarmos os conhecimentos prévios dos alunos, bem como as principais dificuldades que eles apresentavam quanto ao assunto funções.

Sobre as tarefas alternativas aplicadas junto a esse grupo percebeu-se que o trabalho efetuado influenciou positivamente no processo de ensino e aprendizagem desses alunos. Ao realizarem a avaliação diagnóstica inicial, verificamos que os alunos demonstraram possuir grandes dificuldades sobre o assunto. Entretanto, no decorrer do trabalho, verificamos que as resoluções foram se apresentando de forma mais clara, com menos erros conceituais. Ademais, embora nem todos os grupos tenham alcançado o mesmo nível de compreensão nas atividades realizadas, foi possível observar um envolvimento e um crescimento cognitivo de uma parte significativa dos alunos.

Para nós, a evidência mais clara da ocorrência da aprendizagem significativa durante todo o processo de ensino esteve na utilização de tarefas de aprendizagem que, ao se apresentarem em níveis cada vez mais elaborados, se mostraram sequencialmente dependentes umas das outras, onde os alunos tiveram necessariamente que apresentar um domínio dos conceitos precedentes para que assim pudessem seguir na busca pela resolução das tarefas subsequentes; ou seja, houve transferência de conhecimento de uma situação-problema para outra. Isso parece ter atuado como um facilitador na aquisição da estrutura conceitual.

Vale salientar que Moreira (1995) aponta que uma das tarefas fundamentais do professor, no contexto da aprendizagem significativa, é identificar na estrutura do material os conceitos unificadores e inclusivos com maior poder exploratório e organizá-los de modo a englobar os menos inclusivos. De fato, buscamos, com as atividades propostas, apresentar os conteúdos inicialmente de forma mais exploratória, incentivando o estabelecimento de relações entre 
as situações-problema e os conceitos matemáticos necessários, de forma que o conhecimento desses conceitos foi sendo apreendido de maneira cada vez mais profunda.

Com relação ao questionário final aplicado aos alunos, verificamos que o minicurso foi bem avaliado. A maioria considerou o assunto importante e a linguagem utilizada adequada. Das três atividades trabalhadas, identificamos, por esse questionário e pela observação diária, que os alunos gostaram mais da primeira atividade, a qual se referia à procura de emprego. A nosso ver isso está relacionado à natureza do assunto, o tema pode ter despertado o interesse dos alunos, talvez em função do contexto social no qual eles estavam inseridos eles já trabalhavam e, portanto, viviam esta realidade. Assim, pareceu-nos que quanto mais familiar o assunto ao aluno, maior será seu envolvimento com as atividades; o que ressalta a importância da adequação da contextualização dos conteúdos no ensino de matemática. No contexto da teoria de aprendizagem significativa, entendemos que uma contextualização adequada dos conteúdos favoreceu uma maior disposição dos alunos em relacionar de maneira substancial e não arbitrária com o novo material.

\section{Considerações finais}

Alguns autores, tais como Moura (2002), Alonso e Moraes (2003) e Ponte (2003) têm argumentado que os conceitos algébricos, quando estudados com ênfase no formalismo e no rigor matemático, trabalhando memorização e repetição de conteúdos e fórmulas, podem causar grandes dificuldades quanto ao entendimento dos alunos. Concordamos com a colocação de Perrenoud (2000, p. 9) ao afirmar que "diferenciar o ensino é fazer com que cada aprendiz vivencie, tão frequentemente quanto possível, situações fecundas de aprendizagem".

É fato que os alunos frequentam uma escola que, muitas vezes, ainda concebe o conhecimento como algo muito distante da realidade, pouco aproveitável ou significativo nas suas atividades cotidianas. Em sua teoria, Ausubel (1982) apresenta uma aprendizagem que tenha como ambiente uma comunicação eficaz, que respeite e conduza o aluno a se ver como parte integrante da construção do novo conhecimento e onde o educador pode diminuir a distância entre a teoria e a prática na escola, ao trabalhar com uma linguagem que, ao mesmo tempo, desafie e leve o aluno a refletir, conhecendo a sua realidade e os seus anseios.

Consideramos que uma importante contribuição para aprender 
significativamente está no fato de o aluno perceber-se como autogestor de sua formação. Com base nisso, consideramos que o processo educativo, à luz da Teoria de Aprendizagem Significativa, corresponde a um contexto no qual os indivíduos se percebem como sujeitos em constante formação, e buscam ajudar outros sujeitos a se perceberem como tal.

Nosso objetivo, na realização desta pesquisa pautada na aplicação de tarefas didáticas alternativas para o ensino de funções, foi analisar o potencial didático-pedagógico deste tipo de abordagem no Ensino Médio. Uma análise da aplicação efetuada nos permitiu chegar aos seguintes resultados:

Verificamos que essa abordagem mostrou-se como uma alternativa ao favorecimento de uma aprendizagem mais significativa para o ensino de funções, visto que permitiu o estabelecimento de uma relação entre o que os alunos já sabiam e o que lhes estava sendo apresentado, possibilitando o surgimento de diversas soluçôes a partir de seus conhecimentos prévios. Tais fatores, segundo Moreira e Masini (1982), Moura (2002), Tavares (2008), são de extrema relevância para constituírem este tipo de aprendizagem.

Quanto à resolução das tarefas, observamos um favorecimento ao desenvolvimento da criatividade dos alunos na busca de estratégias de solução, além de possibilitar um ambiente de discussão, reflexão e interação entre os mesmos, trabalhar a comunicação, o raciocínio e o registro. Esses são fatores inerentes à resolução de problemas e às atividades de cunho investigativo, e já foram destacados em outros trabalhos, tais como em Fonseca (2000b), Ponte, Brocado e Oliveira (2003), Fiorentini, Fernandes e Cristóvão (2005), Rodrigues (2006), Allevato (2005), Azevedo (1998), Rodrigues (1992) e Dante (1991).

Ainda, percebemos que, embora os alunos inicialmente tenham apresentado resistências ao desenvolvimento deste tipo de atividade, aos poucos eles foram se envolvendo com o trabalho realizado. Alguns autores, tais como Ponte (2003), Fiorentini, Fernandes e Cristóvão (2005) salientam que é comum que os alunos apresentem um estranhamento inicial ao trabalharem com investigações matemáticas, por não conhecerem essa nova metodologia. $\mathrm{O}$ mesmo acontece com a resolução de problemas, já que, como posto em Onuchic e Allevato (2004), muitas vezes, falta no aluno motivação e vontade para trabalhar com situações que necessitam de um exercício mental para realização de tais atividades, visto que eles estão inseridos num contexto onde o pensar quase não é exigido, todas as estratégias estão prontas e ao seu alcance, e a memorização e reprodução são fatores considerados como únicos e suficientes.

Assim, na abordagem focalizada, concebemos os estudantes como 
participantes ativos da construção do conhecimento, o professor como mediador dessa construção, e realização do trabalho em grupo, como de extrema importância durante todo o processo de ensino e aprendizagem.

Quanto às dificuldades apresentadas durante as resoluções, destacamos, principalmente, aquelas referentes às generalizações e formalizações dos resultados; do nosso ponto de vista, estas dizem respeito à dificuldade dos alunos de passar do nível intuitivo do conhecimento para o lógico. Assim, entendemos que esse aspecto realmente exige um grau de autonomia maior do aprendiz frente ao conhecimento.

Ainda sobre esse aspecto, observamos que o papel da Professora Aplicadora mostrou-se fundamental, uma vez que, ao fazer o fechamento das atividades, uma discussão sobre as diversas resoluções foi promovida, culminando nas generalizações e formalizações dos conceitos.

Verificamos, também, que a resolução da primeira despertou maior interesse e envolvimento dos alunos. Salientamos que a contextualização dessa tarefa parecia estar mais diretamente relacionada ao cotidiano dos alunos, ou seja, eles demonstraram que estavam familiarizados com o assunto abordado nessa tarefa. De forma geral, os PCN destacam a importância da contextualização: “[...] aprender Matemática de uma forma contextualizada, integrada e relacionada a outros conhecimentos traz em si o desenvolvimento de competências e habilidades que são essencialmente formadoras". (BRASIL, 1999, p. 111). Esse fato parece nos indicar que tarefas alternativas, tais como as que abordamos neste artigo, tornam-se ainda mais potentes do ponto de vista didático-pedagógico, quando contextualizadas de maneira a considerar situações vivenciadas ou peculiares ao cotidiano do aluno.

Os dados apresentados neste trabalho mostram que, embora não seja fácil mudar a tradição do processo de ensino e aprendizagem de matemática, há indicações de que é possível explorar tais metodologias com êxito. Verificamos que, apesar dos alunos terem apresentado dificuldades iniciais com as novas metodologias, eles tiveram um bom envolvimento com o trabalho realizado, e o grau de participação e motivação foi aumentando à medida que iam se familiarizando com esse tipo de tarefa, favorecendo uma aprendizagem mais significativa dos conceitos de funções e suas aplicações. Vale salientar que, no contexto da teoria de aprendizagem significativa, a motivação é um fator imprescindível para ocorrência desse tipo de aprendizagem, pois, como salienta Novak (1981), mesmo que os alunos tenham os conceitos subsunçores desejados para aprender, é preciso que eles estejam motivados. Desta forma, segundo esse autor, a motivação como um impulso cognitivo está inclusa no processo de 
aprendizagem.

Portanto, nesta pesquisa, verificamos que tarefas tais como as que tratamos neste artigo favorecem uma aprendizagem mais significativa aos alunos, permitindo uma maior compreensão conceitual, tornando-se ainda mais potentes quando se considera o contexto sócio-cultural dos alunos. Desse modo, entendemos que esta investigação apresenta indícios de que o desenvolvimento de Investigações Matemáticas e Resolução de Problemas em sala de aula, incorporadas à Proposta Pedagógica de Meneghetti e Bicudo (2003), representam um contexto de aprendizagem rico e desafiador.

\section{Agradecimento}

As autoras agradecem à FAPESP pelo apoio financeiro concedido.

\section{Referências}

ALLEVATO, N. S. G. Associando o computador à resolução de problemas fechados: análise de uma experiência. 2005, 361f. Tese (Doutorado em Educação Matemática) Instituto de Geociências e Ciências Exatas, Universidade Estadual Paulista, Rio Claro, SP, 2005.

ALONSO, E. P.; MORAES, M. S. S. (Orgs.). Uma alternativa política-social para o ensino de Funções no Ensino Médio. In: SEMINÁRIO INTERNACIONAL DE PESQUISA EM EDUCAÇÃO MATEMÁTICA, 2., 2003, Santos,SP. Anais... São Paulo: SBEM, 2003. 1 CD-ROM.

AUSUBEL, D. P., NOVAK, J. D., HANESIAN, H. Psicologia educacional. Rio de Janeiro: Interamericana. 1978, 625p.

AUSUBEL, D. P. A aprendizagem significativa: a teoria de David Ausubel. São Paulo: Moraes, 1982.

AZEVEDO, L. L. Uma proposta de mudança, na licenciatura em matemática do ICLMA, apoiada na metodologia de ensino de matemática via resolução de problemas. 1998, 220f. Dissertação (Mestrado em Educação Matemática) - Instituto de Geociências e Ciências Exatas, Universidade Estadual Paulista, Rio Claro/SP, 1998.

BRASIL. Ministério da Educação. Secretaria de Educação Média e Tecnológica. Parâmetros Curriculares Nacionais (PCN) - Ensino Médio, Brasília-DF: editora, 1999. 
BRASIL, MEC, SEB. Orientações Curriculares para o Ensino Médio. Ciências da Natureza, Matemática e suas Tecnologias. Brasília: MEC, SEB, 2006.

BRASIL. Orientações Educacionais Complementares aos Parâmetros Curriculares Nacionais (PCN+) - Ensino Médio, Brasília-DF, 2002.

CARVALHO, D. L. Metodologia do ensino da Matemática. São Paulo: Cortez, 1994. DANTE, L. R. Didática da resolução de problemas de matemática. 2. ed. São Paulo: Ática, 1991.

ERNEST, P. Investigações, resolução de problemas e pedagogia. In: P. Abrantes, L. C. Leal \& J. P. Ponte (Orgs.). Investigar para aprender matemática: Textos selecionados. Lisboa: Projeto Matemática para todos e Associação dos Professores de Matemática, 1996, p. 25 - 47.

FIORENTINI, D. Alguns Modos de Ver e Conceber o Ensino da Matemática no Brasil. Zetetiké, Campinas, ano 3, n. 4, p. 1 - 37, nov. 1995.

FIORENTINI, D; MIORIN, M. A.; MIGUEL, A. Contribuição para um Repensar a Educação Algébrica Elementar. Pro-Posições, Campinas, v. 4, n. 1 [10], p. 78 - 91, mar. 1993.

FIORENTINI, D.; FERNANDES, F. L. P.; CRISTOVÃO, E. M. Um estudo das potencialidades pedagógicas das investigações matemáticas no desenvolvimento do pensamento algébrico. In: CONGRESSO IBERO-AMERICANO DE EDUCAÇÃO MATEMÁTICA, 5., 2005, Porto, Portugal. Anais... Lisboa: APM, 2005. v.1. p.1 - 13, CD-ROM.

FONSECA, H., BRUNHEIRA, L.; PONTE, J. P. As actividades de investigação, o professor e a aula de matemática. . In: PROFMAT, 1999, Lisboa, Portugal. Actas... Lisboa: APM, 1999. p. 91 - 101.

FONSECA, H. Os Processos Matemáticos e o discurso em atividades de investigação em sala de aula, 2000. 208 f. Dissertação (Mestrado em Ensino de Matemática). Faculdade de Ciências, Universidade de Lisboa, Lisboa, Portugal, 2000a.

FONSECA, H. Aprender a ensinar investigando. In: GRUPO DE TRABALHO DE INVESTIGAÇÃO (Org). Refletir e investigar sobre a prática profissional. Lisboa: APM. 2000b, p. 177 - 188.

FREGE,G. The Foundations of Arithmetic. English Translation by J. L. Austin. Oxford: Blackwell, 1959. 
FREGE, G. Begrissffchrift, a Formula Language, Modeled upon that of Arithmetic, for Pure Thought. In: HEIJENOORT, V. From Frege to Gödel: A Source Book Mathematical logic 1879- 1931. Cambridge: Havard University Press. 1979, p. 1 - 82.

GAZIRE, E. S. Perspectivas da resolução de problemas em Educação Matemática. 1988, 170f. Dissertação (Mestrado em Educação Matemática) - Instituto de Geociências e Ciências Exatas, Universidade Estadual Paulista. Rio Claro/SP, 1988.

GOLDENBERG, E. Quatro funções da investigação na aula de matemática. In: ABRANTES, P. et. al. (Orgs.). Investigações matemáticas na aula e no currículo. Lisboa: Projeto Matemática para todos e Associação dos Professores de Matemática. 1999, p. 35 - 49.

LUDKE, M.; ANDRÉ, M. E. D. A. Pesquisa em Educação: abordagens qualitativas. São Paulo: EPU, 1986.

MANDARINO, M. C. F., Os professores e a arte de formular problemas contextualizados, 2002. Disponível em: <http://www.bienasbm.ufba.br/OF12.pdf> . Acesso em: 03 ago. 2008.

MAURI, T. O que faz com que o aluno e a aluna aprendam os conteúdos escolares. In: COOL, C. et al. O Construtivismo na sala-de-aula. São Paulo: Editora Ática, 2003, p. $79-122$.

MENEGHETTI, R. C. G. O Intuitivo e o Lógico no Conhecimento Matemático: Uma análise à luz da história e da filosofia da matemática. 2001, 141f. Tese (Doutorado em Educação Matemática) - Instituto de Geociências e Ciências Exatas, Universidade Estadual Paulista, Rio Claro, SP, 2001.

MENEGHETTI, R. C. G. O Intuitivo e o Lógico no Conhecimento Matemático: análise de uma proposta pedagógica em relação a abordagens filosóficas atuais e ao contexto educacional da matemática. Bolema, Rio Claro, v. 22, n. 32, p. 161 - 188, abril. 2009.

MENEGHETTI, R. C. G.; BICUDO, I. Uma discussão sobre a Constituição do Saber Matemático e seus Reflexos na Educação Matemática. Bolema, Rio Claro, ano 16, n. 19, p. $58-72.2003$.

MENEGHETTI, R. C. G.; NUNES, A. C. Atividades Lúdicas e Experimentais para o ensino de frações incorporadas a uma proposta pedagógica. Educação Matemática em Revista, São Paulo, Ano 13, n. 20/21, p. 77 - 86, dez. 2006.

MOREIRA, M. A.; MASINI, E. F. S. Aprendizagem Significativa: a teoria de David Ausubel. São Paulo: Moraes, 1982. 
MOREIRA, M. A. A Teoria de Ausubel. In: MOREIRA, M. A. Ensino e aprendizagem: enfoques teóricos. São Paulo, Editora Moraes, 1995, p. 61 - 73.

MOREIRA, M. A. Aprendizagem significativa. Brasília: Editora Universidade de Brasília, 1999.

MOURA, A. R. L. O Lógico-histórico: uma perspectiva para o ensino de álgebra. In: SEMINÁRIO DE INVESTIGAÇÃO EM EDUCAÇÃO MATEMÁTICA, 13., 2002, Viseu. Actas... Viana do Castelo: APM, p. 345 - 363.

NOVAK, J. D. Uma teoria de educação. Tradução de M. A. Moreira. São Paulo: Pioneira, 1981.

ONUCHIC, L. R., ALLEVATO, N. S. G. Novas reflexões sobre o ensino aprendizagem de matemática através da resolução de problemas. In: BICUDO, M. A. V.; BORBA, M. C. (Orgs). Educação Matemática - pesquisa em movimento. São Paulo: Cortez, 2004. p. $213-231$.

ONUCHIC, L. R. Ensino-aprendizagem de Matemática através da resolução de problemas. In: BICUDO, M. A.V. (Org). Pesquisa em Educação Matemática: Concepções \& Perspectivas. Editora UNESP, São Paulo (SP), 1999, p. 199 - 218.

PERRENOUD, P. Pedagogia diferenciada: das intenções à ação. Porto Alegre: Artes Médicas, 2000, p. 183.

PINHEIRO, N. A. M. Educação crítico - reflexiva para um Ensino Médio cientifico tecnológico: a contribuição do enfoque CTS para o ensino-aprendizagem do conhecimento matemático. 2005, 306f. Tese (Doutorado em Educação Cientifica e Tecnológica) - Instituto de Ciência e Tecnologia, Universidade Federal de Santa Catarina, Florianópolis, 2005.

PONTE, J. P. Investigar, ensinar e aprender. In: PROFMAT, 2003, Lisboa, Portugal. Actas... Lisboa: APM, 2003, p. 25-39. 1 CD-ROM.

PONTE, J. P. et. al. Didactica da Matemática. Lisboa: Departamento do Ensino Secundário, Ministério da Educação, 1997. p. 153-180, Cap.4.

PONTE, J. P.; BROCARDO, J.; OLIVEIRA, H. Investigações matemáticas na sala de aula. Belo Horizonte: Autêntica, 2003.

PONTE, J. P., MATOS, F. Processos Cognitivos e Interações Sociais nas Investigações Matemáticas. In ABRANTES, P., LEAL, L. C.; PONTE, J. P. (Orgs.) Investigar para aprender matemática - Textos selecionados. Lisboa: Projeto MPT e APM, 1998, p. 119 - 137. 
POZO, J. I. (Org.) A solução de problemas: aprender a resolver, resolver para aprender. Porto Alegre: Artmed, 1998.

ROMANATTO, M. C. O livro didático: alcances e limites, 2008. Disponível em: <http:/ /www.sbempaulista.org.br/epem/anais/mesas_redondas/mr19Mauro.doc $>$. Acesso em: 27 jun. 2010.

RODRIGUES, I. C., Resolução de Problemas em Aulas de Matemática para alunos de $1^{\mathrm{a}}$ a $4^{\mathrm{a}}$ séries do Ensino Fundamental e a Atuação dos Professores, 2006, $204 \mathrm{f}$. Dissertação (Mestrado Profissional em Ensino de Matemática) - Pontifícia Universidade Católica, São Paulo, 2006.

RODRIGUES, V. Resolução de Problemas como estratégia para incentivar e desenvolver criatividade dos alunos na prática educativa matemática. 1992, $183 \mathrm{f}$. Dissertação (Mestrado em Educação Matemática). Instituto de Geociências e Ciências Exatas, Universidade Estadual Paulista, Rio Claro/SP, 1992.

SÃO PAULO (Estado). Proposta Curricular para o Ensino de Matemática: $2^{\circ}$ grau. São Paulo: SE/CENP, 1991.

SÃO PAUlO (Estado) Proposta Curricular do Estado de São Paulo: Matemática (Ensino Fundamental - ciclo II e Ensino Médio): $1^{\circ}$ grau. São Paulo, SEE/CENP, 2008.

SERRAZINA, L. et. al O papel das investigações matemáticas e profissionais na formação inicial de professores. In: PONTE, J. P. et al. (Orgs.). Actividades de investigação na aprendizagem da matemática e na formação de professores. Lisboa: SEM-SPCE, 2002, p. 41-58.

TAVARES, R. Aprendizagem significativa e o ensino de ciências. Ciência e Cognição, Rio de Janeiro, v. 13, n. 1, p. 94-100, mar. 2008. Disponível em <http:// www.cienciasecognicao.org/revista/index.php/cec/issue/archive >. Acesso em: 07 mai. 2008.

ZABALA, A. Os Enfoques Didáticos. In: In: COOL, C.; ZABALA, A.; MARTIN, E.; SOLÉ, I.; ONRUBIA., J; MIRAS., M e MAURI,T. O Construtivismo na sala-de-aula. São Paulo: Editora Ática, 2003, p. 153 - 196. Cap 6.

Submetido em Julho de 2010. Aprovado em Novembro de 2010. 
